\section{Bilateral pneumothorax caused by methicillin resistance Staphylococcus aureus; a disastrous pneumonic sequence}

\section{Introduction}

Methicillin - resistant Staphylococcus aureus (MRSA) is a relatively common pathogen responsible for skin and soft tissue infections. However, reports of this pathogen causing severe necrotizing pneumonia are rare and even scarcer to be complicated with bilateral pneumothorax [1-4]. This bacterium was first described in 1880's, in which was recognized to be a fatal pathogen able to caused death in immunocompromised and immunocompetent patients (FIGURES 1-4). We describe a case of a young adult with history of Hepatitis C and intravenous drug usage of cocaine and heroine that came to our institution due to generalized malaise of one week of evolution associated with unquantified fever and chills, without chest pain or shortness of breath. Upon evaluation patient meeting sepsis criteria with leukocytosis, renal failure, multiple electrolyte disturbances, and imaging studies consistent with bilateral pulmonary infiltrates, that in a couple of days became complicated with bilateral pneumothorax with subsequent blood cultures positive for MRSA [5-8].

\section{Christian Castillo}

Latorre*

Ricardo E Bauza Vinas

Hilton Alemar Hernández

Jessica Castellanos Diaz

\section{Michael Cruz Caliz}

San Juan City Hospital, Centro Medico de Puerto Rico

Internal Medicine Residency Program

*Author for correspondence:

cc10332@gmail.com

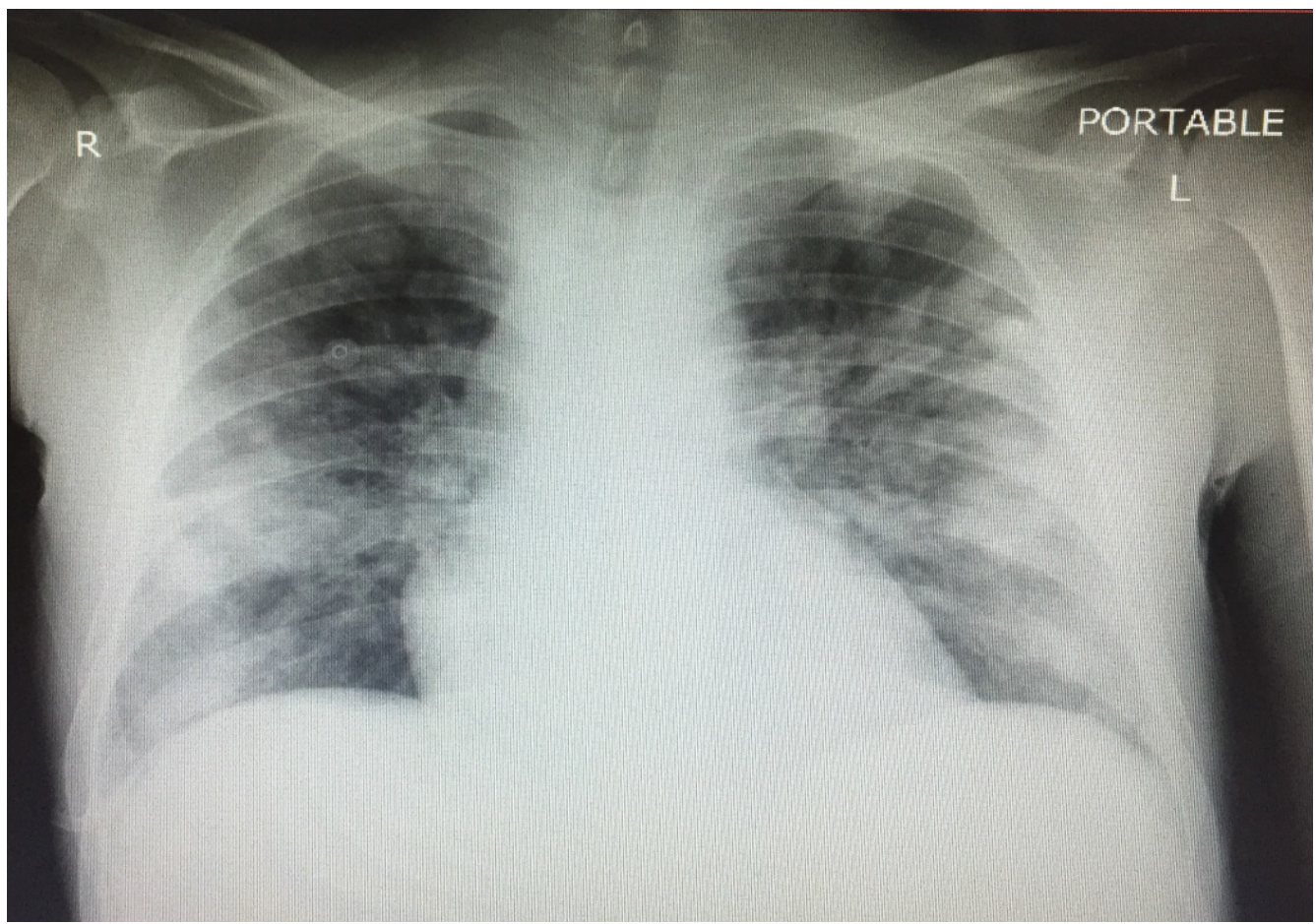

FIGURE 1.Portable chest $x$ ray upon arrival to the ER. Bilateral pulmonary infiltrates with cavitations. 


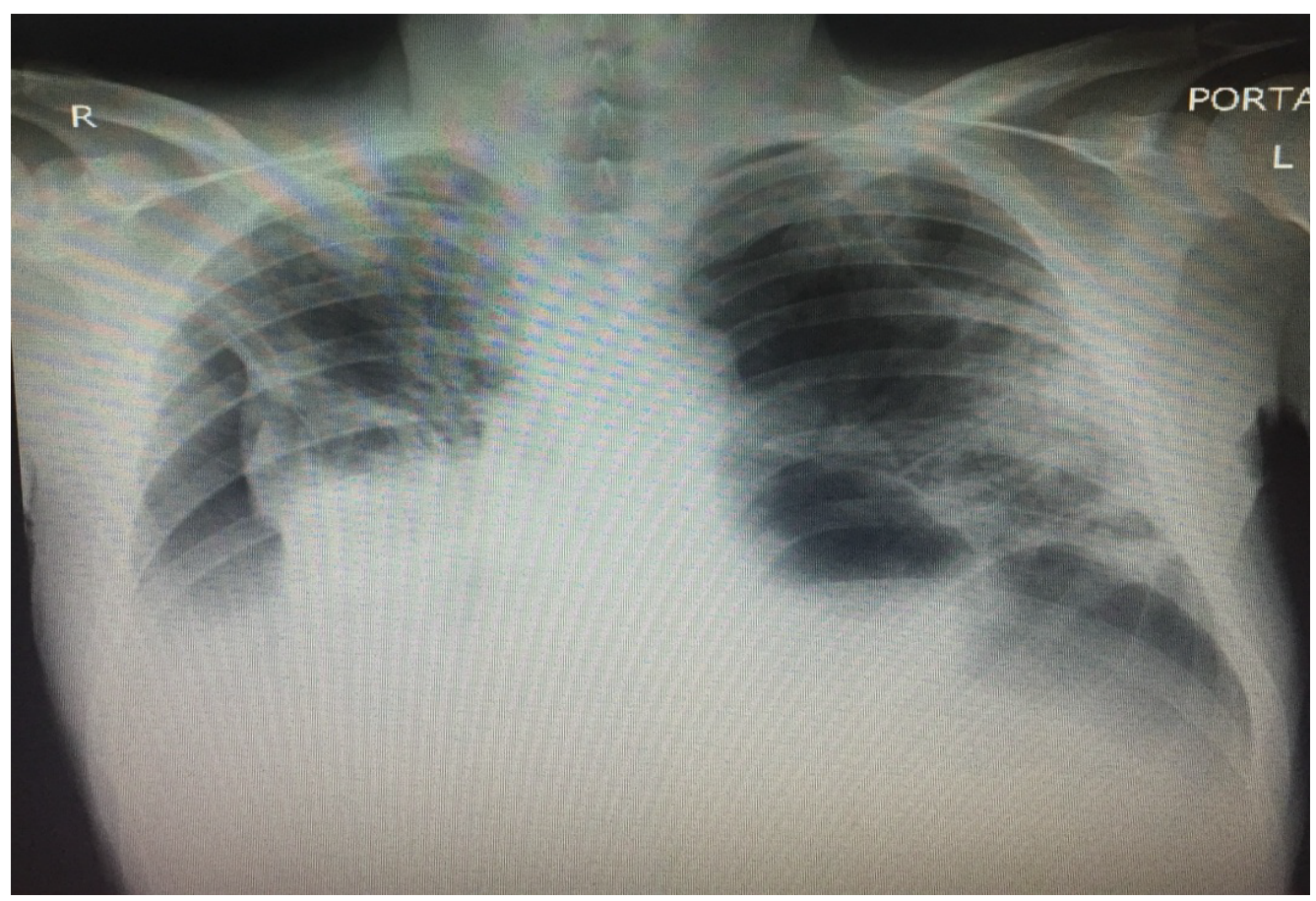

FIGURE 2. Portable chest $\mathrm{x}$ ray three days after admission. Bilateral pneumothorax.

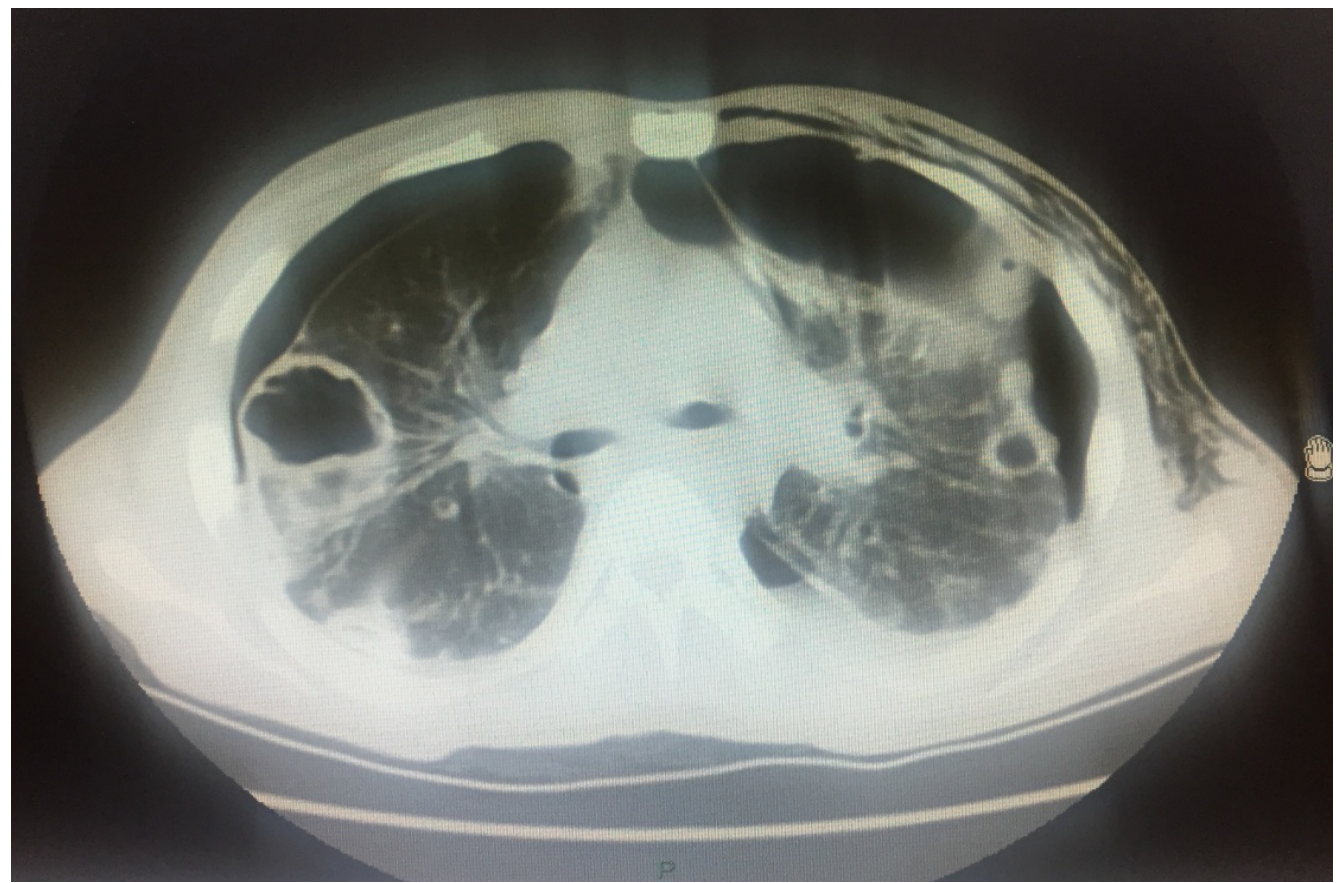

FIGURE 3. Chest CT Scan after chest tube placement. Bilateral pneumothorax with subcutaneous emphysema and multiple cavitations. Right and left chest tubes in place. 


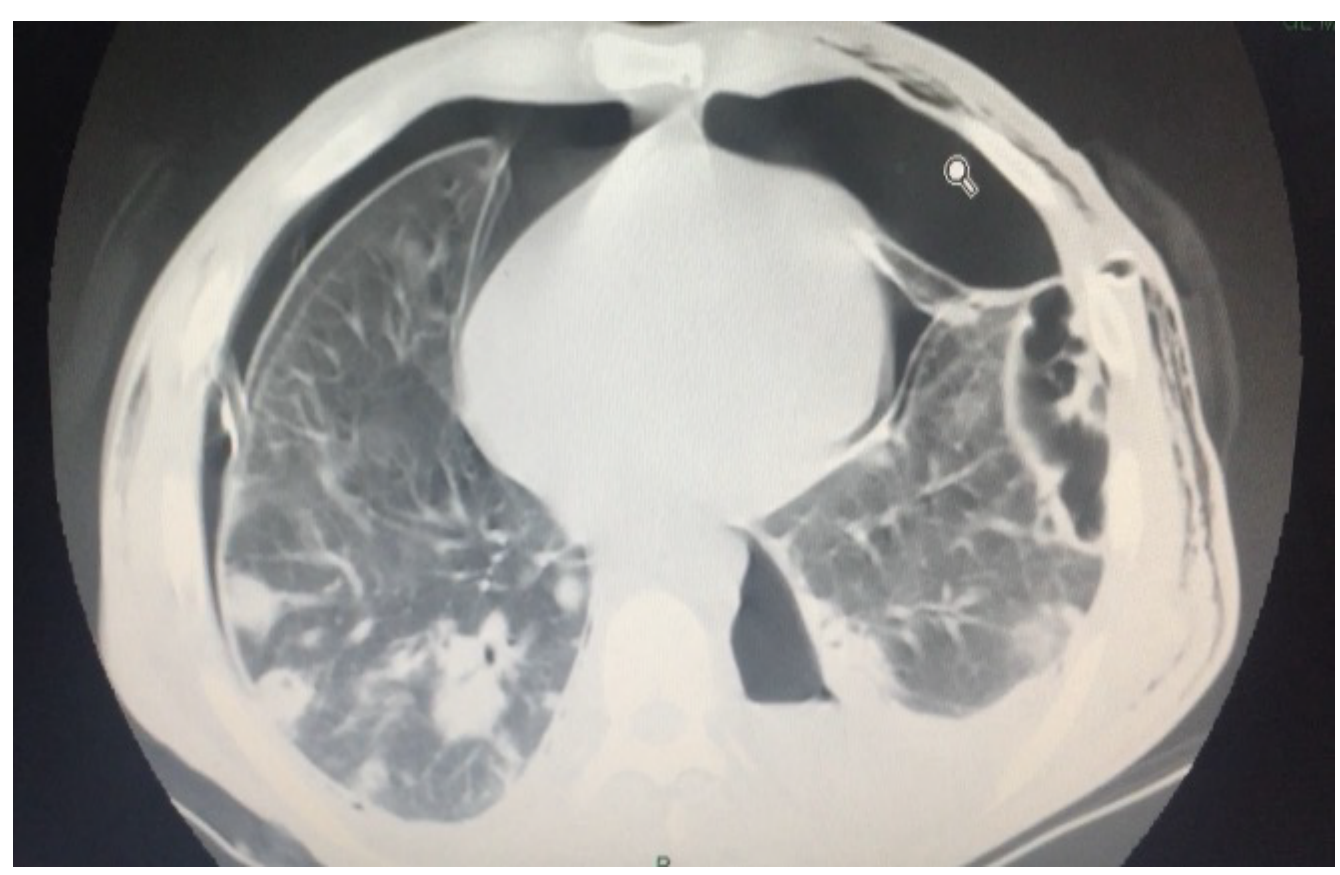

FIGURE 4. Chest CT Scan after chest tube placement. Bilateral pneumothorax with subcutaneous emphysema and multiple cavitations. Right and left chest tubes in place.

\section{Acknowledgements}

The authors are thankful to San Juan City Hospital Internal Medicine section, Infectious diseases, Pneumology - Critical Care and Cardiology

No financial support was provided for the study. 


\section{REFERENCES}

Hidron AI, Low CE, Honig EG, Blumberg HM. Emergence of communityacquired meticillin-resistant Staphylococcus aureus strain USA300 as a cause of necrotising communityonset pneumonia. Lancet Infect. Dis. 9, 384-392. (2009).

Vardakas KZ, Matthaiou DK, Falagas ME. Comparison of community-acquired pneumonia due to methicillinresistant and methicillin-susceptible Staphylococcus aureus producing the Panton-Valentine leukocidin. Int. J. Tuberc. Lung Dis.13, 1476-1485 (2009).

Li HT, Zhang TT, Huang J, et al. Factors associated with the outcome of lifethreatening necrotizing pneumonia due to community-acquired Staphylococcus aureus in adult and adolescent patients. Respiration. 81, 448-460 (2011).

Kallen AJ, Brunkard J, Moore Z, et al. Staphylococcus aureus communityacquired pneumonia during the 2006 to 2007 influenza season. Ann. Emerg. Med. 53, 358-365 (2009).

Castaldo ET, Yang EY. Severe sepsis attributable to communityassociated methicillin-resistant Staphylococcus aureus: an emerging fatal problem. Am. Surg. 73(7), 684-687 (2007).

Gillet Y, Vanhems P, Lina G, et al.
Factors predicting mortality in necrotizing community-acquired pneumonia caused by Staphylococcus aureus containing Panton-Valentine leukocidin. Clin. Infect. Dis. 45(3), 315-321 (2007).

Diep BA, Gill SR, Chang RF, et al. Complete genome sequence of USA300, an epidemic clone of community-acquired meticillinresistant Staphylococcus aureus. Lancet 367(9512), 731-739 (2006).

Laterre PF. Severe community acquired pneumonia update: Mortality, mechanisms and medical intervention. Cri.t Care. 12(Supp 6), S1 (2008).

This special issue on Current Trends in Clinical Research was edited by Dr. Mohamed Elsayed. 